\title{
Study on the Impact of "Gerayo Amahoro Policy" on Road Traffic Accidents Reduction in Rwanda
}

\author{
Jean de Dieu Gatesi ${ }^{*},{ }^{(\mathbb{D})}$, Bin Shuai ${ }^{1}$ (D) , Rachel Mukamana ${ }^{2(\mathbb{D})}$, Jean de Dieu Mutabaruka ${ }^{3(\mathbb{D})}$ \\ ${ }^{*} P h D$ candidate in Traffic Engineering at Southwest Jiaotong University, P.R.China \\ ${ }^{1}$ Professor in School of Transportion and Logistics Engineering, SWJTU-Chengdu, P.R.China \\ ${ }^{2}$ Assistant Lecturer in Civil Engineering at CST-University of R wanda \\ ${ }^{3}$ Lecturer in Civil Engineering at CST-University of Rwanda
}

\section{Keywords}

Road traffic accidents,

Gerayo Amahoro,

Statistical analysis,

Impact factors,

Counter measures.

\begin{abstract}
The global status report on road safety declared that the number of annual road traffic deaths has reached 1.35 million. In Rwanda, considering the raising number of vehicles in line with the economy growth and the above 48.90/000 ratio of deaths per registered vehicles; the lives of people are therefore increasingly exposed to road traffic crashes. This study therefore aims to utilize statistical methods for assessing the impact of Gerayo Amahoro policy on Road Traffic Accidents reduction in Rwanda and propose counter measures that could help the decision makers in minimizing the losses caused by Road Traffic Accidents. secondary data related to road traffic accidents have been collected by using questionnaire from Rwanda National Police with the study period from 2016 up to 2020 inclusive. Analysis was done by using graphics and chi-square methods in excel and SPSS software. The results indicated that GERAYO AMAHORO policy plays the greatest role in reduction of RTAs in Rwanda due to the number of RTAs happened before the implementation of GERAYO AMAHORO which was high as compared to the total number of RTAs after implementation of GERAYO AMAHORO policy. This research conclude that negligence, over speed, bad maneuver and over drunk are mostly causes and responsible for the occurrence of RTAs in Rwanda; indicated that Vehicle types mostly related to RTAs were moto-cycles, cars and 4 wheel vehicles and the mostly victims related to RTAs were motocyclists, passengers and pedestrians.
\end{abstract}

\section{Introduction}

The global status report on road safety declared that the number of annual road traffic deaths has reached 1.35 million. A Road traffic injury is now the leading cause of deaths for the children and young adults aged between 5 to 29 years old. The burden of road traffic injuries and deaths is disproportionately borne by vulnerable road users (pedestrians, cyclists and motorcyclists); in particular, those are living in low and middle income countries; where the growing number of deaths is fueled by transport that is increasingly motorized. Between 2013-2016, no reduction in the number of traffic deaths were observed in any low income country, while some reductions were observed in 48 middle and high income countries. It is also reported that nearly 3,700 people dying on the world's road every day and about 50 million other survived with serious injuries (WHO, Global status report on road safety, 2018). Three indicators are mainly used to measure road safety performance and compare safety levels across the different countries; the number of fatalities per population (mortality rates), the number of fatalities per distance travelled by motorized vehicles (fatality risk), the number of fatalities per number of registered motorized vehicles. Each indicator has its pros and cons and in all cases, country comparisons should be interpreted with greatest care; especially between countries with different levels of motorization (ITF, Road safety annual report, 219). Improving road safety and the number of causalities requires permanent and continuous action based on the analysis of solid data. In some countries, the easy measures have now been implemented and to reduce further the number of road causalities, including serious injuries; it is necessary to exploit available data on the circumstances of crashes, the mechanism leading to crashes and their severity, the road users involved etc., as well as to take proactive risk assessment of the road traffic network (ITF, Road safety annual report, 2019). Strengthening efforts to improve the road safety data available for low and middle income countries; reliability and timely road safety data are essential components of sound road safety policy. Most high income counties have functioning crash data collection systems. Huge efforts are needed in most low and middle income countries to ensure the minimum set of data is collected to allow a robust diagnosis of the respective road safety situation. Road safety data collection and analysis could not be limited to fatality data. Around 50 million people are seriously injured in the world every year; but reliable data on serious injuries are very scarce even in the best performing countries. It is recommended that all countries need to improve the collection and analysis of road traffic injuries data (ITF, 2017). Drink-driving, speeding and the no-wearing seat belts in cars and helmets on motorcycles are leading contributors to road crash resulting in serious injuries and fatalities. These represent the common safety challenge in all counties and can be tackled through establishing the international best practices even in very different contexts (ITF, Road safety annual report, 2017). For success of road safety laws, the many countries are recommended to put in practice the following enforcements; reducing speed of motorized vehicles, increasing motorcycle helmet use, reducing drink-driving, increase seat belts use in cars, increase child restraints use, reducing drugdriving, reducing distracted driving (WHO, Global status report on road safety, 2015). The overall global road traffic fatality rate is 18 per 100000 population. However, middle income countries have the highest annually road traffic rate at 20.1 per 100000 populations, while the rate in high income countries is lowest at 8.7 per 100000 populations. Over a third of road traffic deaths in low and middle income countries are among pedestrians and cyclists. Eighty per cent of road deaths occur in middle income countries, which account for 
$72 \%$ of the world's population; but only $52 \%$ of the world's registered vehicles. This indicates that these countries bear a disproportionately high burden of road traffic death relative to their level of motorizations (WHO, 2013; WHO, 2015. It is also reported that the countries in Africa and south-east Asia have regional rates of road traffic deaths higher than the global rate with 26.6 and 20.7 deaths per 100000 population respectively. This is followed by countries in east Mediterranean and western pacific, which have regional rates comparable with the global rate with 18 and16.9 deaths per 100000 populations respectively. Countries in the America and Europe have the lowest regional rates of 15.6 and 9.3 deaths per 100000 people respectively. In term of progress made, in three of the six regions (America, Europe, Western pacific), the rates of deaths have decreases from 2013-2016(WHO, 2018; WHO, America region, 2015; WHO, Europe region, 2015). Globally, Africa region possesses only $2 \%$ of the world's vehicles and it contributes $16 \%$ to the global deaths. Nigeria and South Africa have the highest fatality rates of 33.7 and 31.9 deaths per 100 000 population per year respectively in the region. More than one in four deaths in the Africa region occur in Nigeria roads, and with six other countries; Democratic Republic of Congo, Ethiopia, Kenya, South Africa, Tanzania and Uganda, are responsible for $64 \%$ of all deaths in the region (WHO, African region, 2013). According to world health organization report, 2018; the African region accounts for $20 \%$ of global road traffic deaths with nearly 272000 deaths. It accounts for $14 \%$ of the total world populations and $3 \%$ of the total number of registered vehicles (WHO, 2018). Road injuries deaths now comprise a relatively large proportion of all deaths in sub-Saharan Africa partly because road traffic deaths in the region are rapidly increasing. The global road traffic deaths toll has risen by $46 \%$ over the last two decades. However, road traffic deaths in sub-Saharan Africa grew almost twice as fast, rising by $84 \%$. The western and south regions of sub-Saharan Africa experienced the highest increases of all regions in the world with a rise of $111 \%$ and $102 \%$, respectively. It should be noted that substantial portion of these increases are simply the results of population growth. Road injury deaths rates in sub-Saharan Africa rose only by $10 \%$ over this period, from 24.4 to 26.9 per 100000 population (Kavi Bhalla et al., 2014). According to world health organization report, 2018; the $3 / 4$ of the East Africa countries have an estimated road traffic fatality rates high than the average Africa rate. Only $38 \%$ of countries have a fatality rate reduction targets in their strategies as reported by world health organization, 4thGlobal status report for road safety 2018.

\section{State of RTAs in Rwanda}

The World Health Organization (WHO, 2018) classifies Rwanda among countries in the red zone with estimated 29.7 deaths per 100,000 people. In their "Global Status Report on Road Safety 2018", the WHO estimates that in Rwanda 3,535 people died of road traffic accidents in 2018; although 593 deaths were reported. According to the Rwanda National Police, motorcyclists are involved in $71 \%$ of total road traffic accidents (Theogene CYIZA and Fred MWASA, 2019).

In Rwanda, considering the raising number of vehicles in line with the economy growth and the above $48.90 / 000$ ratio of deaths per registered vehicles; the lives of people are therefore increasingly exposed to road traffic crashes. RNP and MINIFRA have significantly elaborated and enforced strategies on how to reduce the road traffic crashes, however the trend analysis conducted by (World health organization, $2013,2015,2018$ ) shows a prospect raise of road traffic deaths in a near future. By considering the earlier mentioned studies, it seems that the increase the vehicles number with no comparable infrastructures, it is also being the one causal factor of road traffic deaths in which the security of these vehicles would remain also at risk. According to Rwanda National Police (RNP, 2016); in this period, the country registered 593 fatal crashes,629 serious injuries, 1794 minor injuries with 3347 incidents resulting into property damage only. RNP further declares that these incidents and road traffic crashes claimed the lives of 679Rwandans and 3750 lives in a spell of past six years(MINIFRA, Final transport report, 2018).In Rwanda, from January to September 2018, a total of 437 people lost lives while other 662 people were injured in road crashes; in the same period, a total of
7034 drivers were caught with overtaking in dangerous locations, 6841 drivers by using phone while driving and 1064 drivers with high drunk(Igihe, Road accident report, 2018).According to the latest World health organization report on road traffic crashes, Rwanda is ranked on 7 place worldwide with the total number of deaths 4054 or $7.14 \%$ of total deaths(WHO, 2018).Statistically, RNP declares that at least 532 people died in road crashes between January and September 2019; other705 crashes were registered as serious injuries while over1300 properties were damaged(Igihe, Road accidents report, 2019). Recently, RNP reported that in the past six months of the year 2020, 600 road crashes have been registered in Rwanda. But it was explained that before launching Gerayo Amahoro campaign by RNP, May 2019; road traffic crashes were more than 5000 and killing 500 people each year (Igihe, Road crashes report, 2020). Road traffic crashes are a significant cause of mortality and morbidity in Rwanda. The research on the high risk zones, causal factors, vehicles involved and vulnerable road users for road traffic crashes are urgently required to guide the traffic planners and road safety decision makers in their government policy implementation.

This study therefore aims to utilise statistical methods for assessing the impact of Gerayo Amahoro policy on Road Traffic Accidents reduction in Rwanda and propose counter measures that could help the decision makers in minimizing the losses caused by Road Traffic Accidents. secondary data related to road traffic accidents have been collected by using questionnaire from Rwanda National Police with the study period from 2016 up to 2020 inclusive. The factor influencing the road traffic accidents were evaluated by using the Microsoft excel and SPSS softwares in order to understand well the mostly factor contributed in RTAs. Vehicle types, road users, road victictims were taken into account in this research study. Next section shows the conceptual framework of research analysis and findings.

\section{Materials and Methods}

\subsection{Research design}

Research methodology contains methods and techniques used to get information required to meet research findings that answer the research objectives of this study. The overall methodology of this study is summarized in the below flowchart.

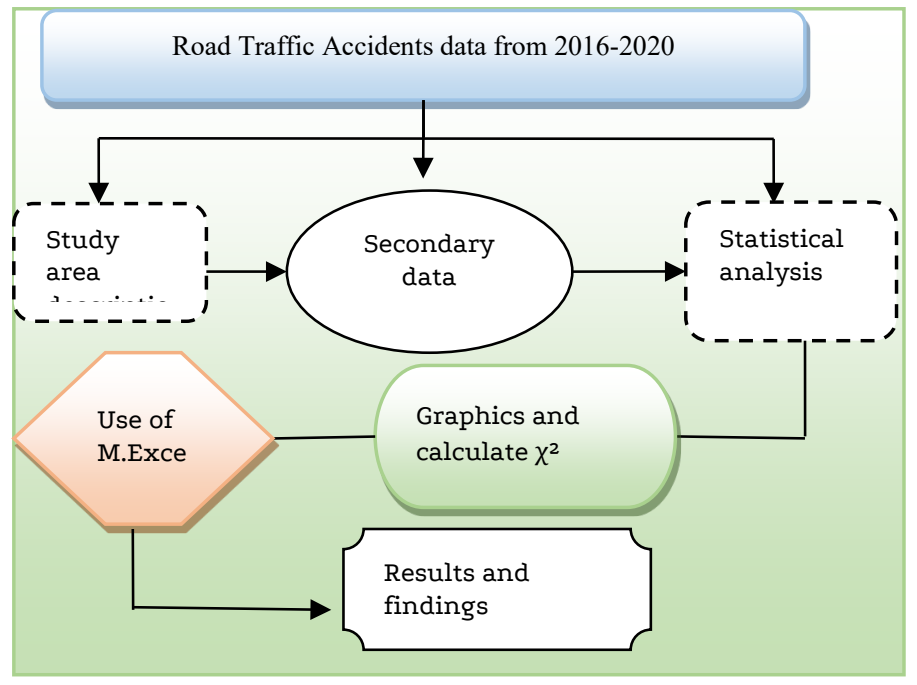

Figure 1. Conceptual framework of research design 


\subsection{Study area}

The study was carried out on 4 provinces of Rwanda including Kigali city. A virtual guide to "the land of a thousand hills". Rwanda is a relative small landlocked, hilly country in central Africa, located south of the equator and east of Lake Kivu (one of the African great lakes). It is bordered by Burundi, Democratic Republic of Congo, Tanzania, and Uganda. The country covers an area of $26,338 \mathrm{~km} 2$ Rwanda has population of 11.5 million people (RNIS, 2016); Rwanda's population density is among the highest in sub-Saharan Africa, Capital and largest city is Kigali. Spoken languages are Kinyarwanda (mother tongue), English and French.

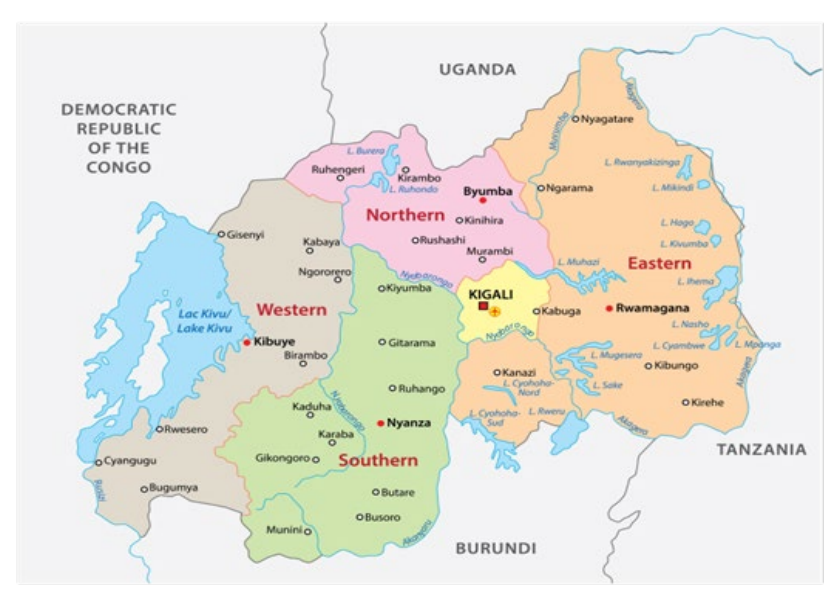

Figure 2. Map of Rwanda with borders(google)

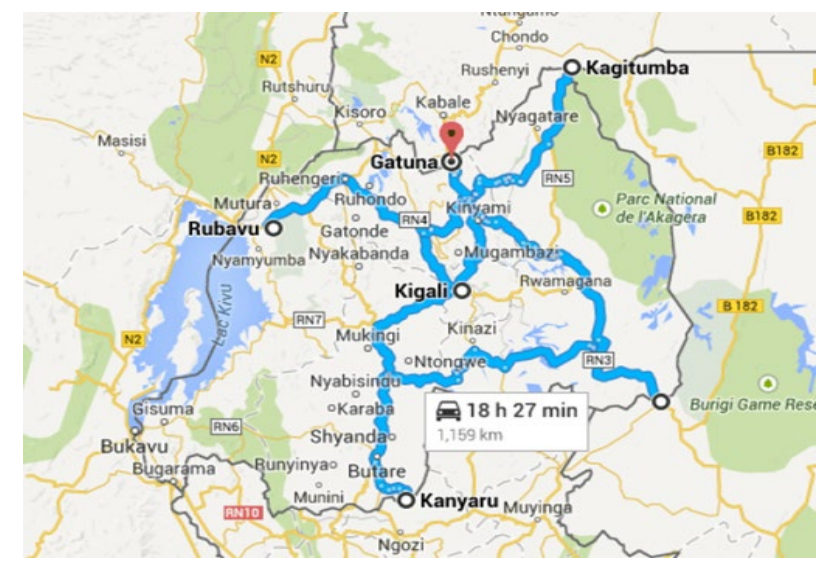

Figure 3. Map of road networks in Rwanda (google)

\subsection{Data collection and processing}

During the research, secondary data related to road traffic accidents have been collected by using questionnaire from Rwanda National Police. The study period was from 2016 up to 2020 inclusive; The Road traffic accidents data are summarized by using tables as shown below. The following items were included in data collection; total number of road traffic accidents by monthly in Rwanda, total number of fatalities, injuries and PDO; types of vehicles involved in road traffic accidents; Causes of road traffic accidents and number of accidents based on the category of road user victims.
Table 1. Shows fatalities, injuries and PDO

\begin{tabular}{lccccc}
\hline $\begin{array}{l}\text { Types of } \\
\text { accidents }\end{array}$ & 2016 & 2017 & 2018 & 2019 & 2020 \\
\hline Fatalities & $10.7 \%$ & $10.8 \%$ & $11.7 \%$ & $15.9 \%$ & $12.5 \%$ \\
Injuries & $53.0 \%$ & $64.7 \%$ & $67.3 \%$ & $77.2 \%$ & $48.0 \%$ \\
PDO & $36.3 \%$ & $24.5 \%$ & $21.1 \%$ & $6.9 \%$ & $39.5 \%$ \\
\hline
\end{tabular}

Data obtained from Rwanda National Police (2020)

Table 2. Shows data of RTAs per month in five years

\begin{tabular}{llllll}
\hline Month & Year & & & & \\
& 2016 & 2017 & 2018 & 2019 & 2020 \\
\hline Jan & $7.95 \%$ & $7.25 \%$ & $7.97 \%$ & $9.65 \%$ & $8.82 \%$ \\
Feb & $8.55 \%$ & $8.53 \%$ & $9.62 \%$ & $9.28 \%$ & $10.1 \%$ \\
March & $8.36 \%$ & $7.82 \%$ & $8.80 \%$ & $9.33 \%$ & $7.36 \%$ \\
April & $7.92 \%$ & $8.48 \%$ & $8.23 \%$ & $8.73 \%$ & $3.21 \%$ \\
May & $8.17 \%$ & $7.06 \%$ & $9.00 \%$ & $8.51 \%$ & $5.89 \%$ \\
June & $7.72 \%$ & $9.18 \%$ & $8.93 \%$ & $7.91 \%$ & $9.06 \%$ \\
July & $8.27 \%$ & $8.13 \%$ & $8.02 \%$ & $8.04 \%$ & $9.27 \%$ \\
Aug & $8.97 \%$ & $8.52 \%$ & $8.29 \%$ & $8.21 \%$ & $8.96 \%$ \\
Sept & $9.23 \%$ & $9.12 \%$ & $7.24 \%$ & $37.61 \%$ & $8.24 \%$ \\
Oct & $7.84 \%$ & $8.05 \%$ & $7.84 \%$ & $7.57 \%$ & $9.42 \%$ \\
Nov & $8.52 \%$ & $8.32 \%$ & $8.04 \%$ & $7.46 \%$ & $8.84 \%$ \\
Dec & $8.50 \%$ & $9.54 \%$ & $8.02 \%$ & $7.72 \%$ & 10.85 \\
& & & & & \\
\hline Total & 6363 & 5754 & 5611 & 4653 & 4174 \\
Mean & 530.25 & 479.5 & 467.58 & 387.75 & 347.8 \\
Std.D & 28.99 & 42.80 & 36.14 & 35.38 & 85.39 \\
\hline
\end{tabular}

Data obtained from Rwanda National Police (2020)

Table 3. Shows vehicles in Road Traffic Accidents

\begin{tabular}{|c|c|c|c|c|c|}
\hline \multirow{2}{*}{$\begin{array}{l}\text { Vehicle } \\
\text { types }\end{array}$} & \multicolumn{5}{|c|}{ Year } \\
\hline & 2016 & 2017 & 2018 & 2019 & 2020 \\
\hline Pickups & $\begin{array}{c}14.00 \\
\%\end{array}$ & $13.12 \%$ & $12.25 \%$ & $12.77 \%$ & $14.4 \%$ \\
\hline Lorry & $\begin{array}{c}10.17 \\
\%\end{array}$ & $11.28 \%$ & $12.16 \%$ & $11.63 \%$ & $14.8 \%$ \\
\hline Buses & $\begin{array}{c}11.60 \\
\%\end{array}$ & $9.48 \%$ & $8.32 \%$ & $8.25 \%$ & $7.44 \%$ \\
\hline 4 wheel & $\begin{array}{c}15.20 \\
\%\end{array}$ & $14.08 \%$ & $12.64 \%$ & $12.87 \%$ & $12.7 \%$ \\
\hline Cars & $\begin{array}{c}23.87 \\
\%\end{array}$ & $22.88 \%$ & $19.87 \%$ & $18.20 \%$ & $17.9 \%$ \\
\hline Moto & $\begin{array}{c}22.01 \\
\%\end{array}$ & $24.81 \%$ & $30.13 \%$ & $30.15 \%$ & $25.6 \%$ \\
\hline Pedal & $3.05 \%$ & $4.27 \%$ & $4.63 \%$ & $6.14 \%$ & $7.13 \%$ \\
\hline Others & $0.10 \%$ & $0.07 \%$ & $0 \%$ & $0 \%$ & $0 \%$ \\
\hline Total & 10454 & 8762 & 8496 & 6862 & 3536 \\
\hline Mean & $\begin{array}{c}1306.7 \\
5\end{array}$ & 1095.25 & 1062 & 857.75 & 442 \\
\hline Std.Dev & $\begin{array}{c}864.4 \\
0 \\
\end{array}$ & 736.94 & 787.29 & 613.69 & 274 \\
\hline
\end{tabular}

Data obtained from Rwanda National Police (2020) 
Table 4. Road traffic accidents based on Causes

\begin{tabular}{|c|c|c|c|c|c|}
\hline \multirow[t]{2}{*}{ Cause } & \multicolumn{5}{|c|}{ Year } \\
\hline & 2016 & 2017 & 2018 & 2019 & 2020 \\
\hline Speeding & $9.30 \%$ & $14.72 \%$ & $20.27 \%$ & $29.21 \%$ & $27.31 \%$ \\
\hline Drunk & $2.55 \%$ & $3.09 \%$ & $3.27 \%$ & $3.42 \%$ & $2.75 \%$ \\
\hline Negligenc & $52.06 \%$ & $48.30 \%$ & $42.27 \%$ & $29.41 \%$ & $26.23 \%$ \\
\hline Bad Maneu & 33.59 & $32.83 \%$ & $33.55 \%$ & $37.29 \%$ & $42.58 \%$ \\
\hline M. faults & $2.00 \%$ & $0.89 \%$ & $0.47 \%$ & $0.49 \%$ & $0.92 \%$ \\
\hline Road cond & $0.41 \%$ & $0.14 \%$ & $0.07 \%$ & $0.115 \%$ & $0.11 \%$ \\
\hline Weather & $0.04 \%$ & $0.02 \%$ & $0.07 \%$ & $0 \%$ & $0.05 \%$ \\
\hline Road sign & $0.02 \%$ & $0 \%$ & $0.02 \%$ & $0.03 \%$ & $0.05 \%$ \\
\hline Others & $0.02 \%$ & $0 \%$ & $0 \%$ & $0.03 \%$ & $0 \%$ \\
\hline Total & 4894 & 4170 & 4071 & 3478 & 1853 \\
\hline Mean & 543.78 & 463.33 & 452.33 & 386.44 & 205.89 \\
\hline Std.Dev & 919.68 & 741.06 & 678.70 & 551.30 & 303.34 \\
\hline
\end{tabular}

Data obtained from Rwanda National Police (2020)

Table 5. RTAs based on road user victim's category

\begin{tabular}{lccccc}
\hline $\begin{array}{l}\text { Road user } \\
\text { victims in \% }\end{array}$ & 2016 & 2017 & 2018 & 2019 & 2020 \\
\hline Drivers & 11.2 & 13.8 & 12.4 & 13.6 & 22.0 \\
Moto-cycle & 43.5 & 47.5 & 44.1 & 41.6 & 34.7 \\
Pedalcycle & 6.0 & 8.2 & 6.8 & 8.5 & 9.4 \\
Passengers & 19.6 & 15.2 & 18.4 & 18.2 & 17.0 \\
Pedestrian & 19.6 & 15.2 & 18.4 & 18.2 & 17.0 \\
\hline
\end{tabular}

Data obtained from Rwanda National Police (2020)

\subsection{Graphical data analysis}

By using the graphical form, the data are plotted in Microsoft Excel sheet. Table 2 and Figure 4 represent the total number of Road Traffic accidents from January to December with study period of 2016-2020. It is revealed that the total number of Road Traffic Accidents (RTAs) happened from January to December of 2016, 2017, 2018, 2019 and 2020 are $6363,5754,5611,4653$ and 4174 respectively. The results of this study showed that RTAs majority 9.23\%(6363) happened in September 2016, 9.54\%(5754) RTAs happened in December 2017, 9.62\%(5611) RTAs happened in February 2018, 9.65\%(4653) RTAs happened in January 2019 and 10.85\%(4174) RTAs happened in December 2020 however RTAs minority 7.72\%(6363) happened in June2016, 7.06\%(5754) RTAs happened in May 2017, 7.24\%(5611) RTAs happened in September 2018, 7.46\%(4174) RTAs happened in November 2019 and 3.21\%(1105) RTAs happened in April 2020.

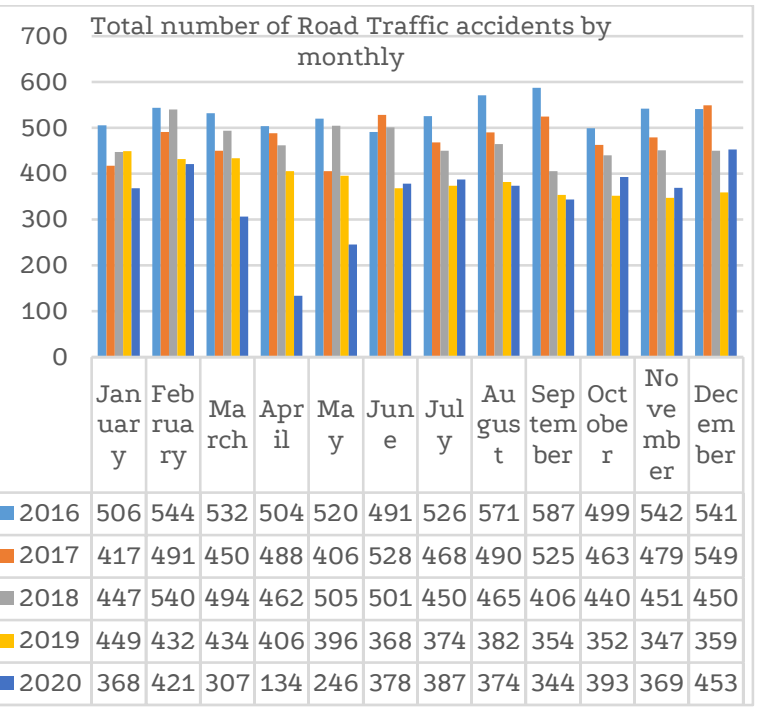

Figure 4. Total number of Road Traffic crashes by monthly in Rwanda

According to Table 2 and figure 4, and Reference to the measures taken to reduce RTAs in Rwanda including Gerayo Amahoro that was launched in May 2019; the results of this study showed the decrease of RTAs from total of 5611 happened in 2018 to the total of 4653 that was happened in 2019 with difference of reduction of 958 RTAs and also a decrease of 4653 RTAs of 2019 to 4174 RTAs of 2020 with difference of reduction of 479 RTAs.

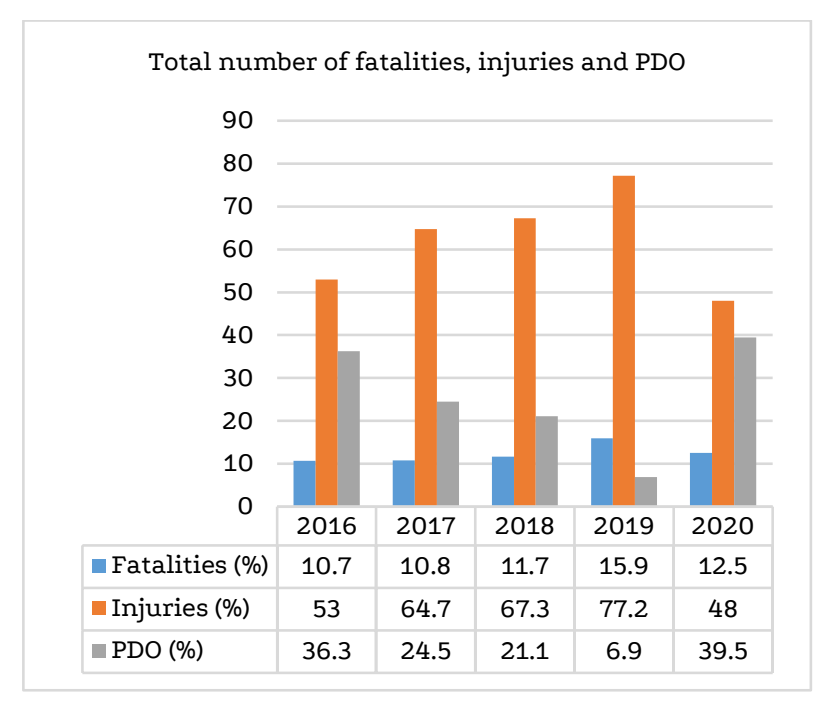

Figure 5. Total number of fatalities, injuries \& PDO

Table 1 and Figure 5, represent the total number of fatalities, injuries and PDO from 2016 to 2020. It is shown that the total number of fatalities resulted from RTAs in year 2016, 2017, 2018, 2019 and 2020 were $10.7 \%, 10.8 \%$, and $11.7 \%, 15.9 \%$ and $12.5 \%$ respectively. The total number of injuries both minor and major resulted from RTAs in year 2016, 2017, 2018, 2019 and 2020 were $53.0 \%, 64.7 \%, 67.3 \%, 77.2 \%$ and 48.0\% respectively; and the total number of PDO resulted from RTAs in year 2016, 2017, 2018, 2019 and 2020 were $36.3 \%, 24.5 \%, 21.1 \%, 6.9 \%$ and $39.5 \%$ respectively. The majority and minority number of fatalities resulted from RTAs was $15.9 \%$ of 2019 and $10.7 \%$ of 2016 respectively. The majority and minority number of injuries both minor and major resulted from RTAs was $77.2 \%$ of 2019 and $48.0 \%$ of 2020 respectively. However, the majority and minority number of PDO resulted from RTAs was $39.5 \%$ of 2020 and $6.9 \%$ of 2019 respectively. 


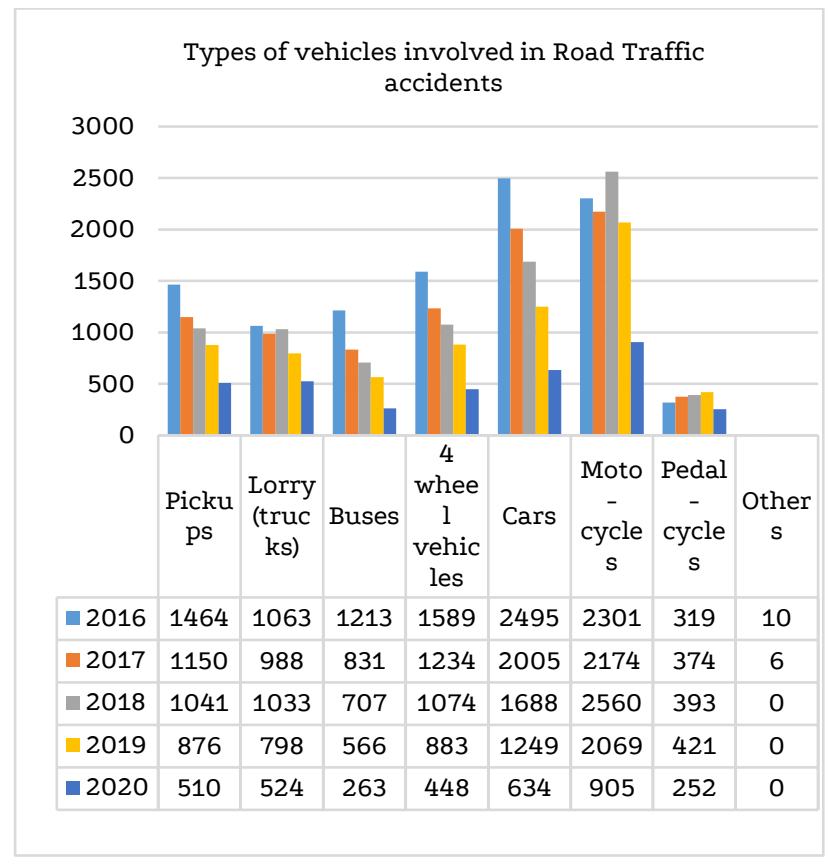

Figure 6. Types of vehicles involved in road traffic accidents

Table 3 and Figure 6 indicate the types of vehicles involved in road traffic crashes from 2016 to 2020. Types of vehicles involved in RTAs were Pickups, Lorry (trucks), buses, 4-wheel vehicle, Cars, Moto-cycles, Pedal-cycles and others with proportions of 1464, 1063, 1213, 1589, 2495, 2301, 319 and 10 in 2016 respectively. In 2017, the proportions were $1150,988,831,1234,2005,2174,374$ and 6 respectively. In 2018 , the proportions were $1041,1033,707,1074,1688,2560,393$ and 0 respectively. In 2019, the proportions were $876,798,566,883,1249,2069,421$ and 0 respectively. In 2020 , the proportions were $510,524,263,448,634,905,252$ and 0 respectively. The results of this study showed that RTAs majority $23.87 \%$ (10454) caused by Cars in 2016, 24.81\% (8762) caused by moto-cycles in 2017, 30.13\% (8496) caused by moto-cycles in $2018,30.15 \%$ (6862) caused by motocycles in 2019 and $25.60 \%$ (3536) caused by moto-cycles in 2020 . However, Minority was caused by others (external factors) with $0.10 \%$ (10454), 0.07\% (8762), 0\% (8496), 0\% (6862) and 0\% (3536) in 2016, 2017 2018,2019 and 2020 respectively. In addition, the results of this study showed that motor-cycles were the most vehicles that were involved in RTAs.

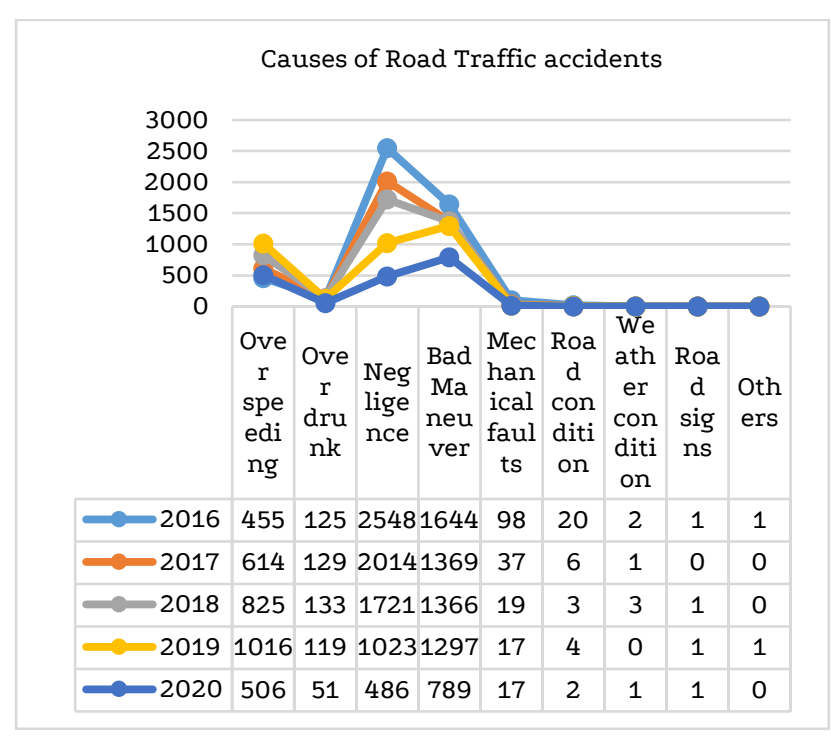

Figure 7. Causes of Road Traffic Crashes
Table 4 and Figure 7 represent the Number of road traffic crashes based on Causes of Road Traffic Crashes from 2016 to 2020. The Causes of RTAs were Over speeding, Over drunk, Negligence, Bad Maneuver, Mechanical faults, Road condition, Weather condition, Road signs and Others with proportions of 455, 125, 2548, 1644, 98, 20 , 2,1 and 1 in 2016 respectively. In 2017, the proportions were 614, 129 , $2014,1369,37,6,1,0$ and 0 respectively. In 2018, the proportions were $825,133,1721,1366,19,3,3,1$ and 0 respectively. In 2019, the proportions were 1016, 119, 1023, 1297, 17, 4, 0, 1 and 1 respectively. In 2020 , the proportions were $506,51,486,789,17,2,1,1$ and 0 respectively. The results of this study showed that negligence was the most factor causing RTAs in 2016,2017,2018 with proportions of $52.06 \%(4894), 48.30 \%(4170)$, 42.27\%(4071) respectively, however bad maneuver was the most factor causing RTAs in 2019, 2020 with proportions of $37.29 \%(3478), 42.58 \%(1853)$ respectively. Mechanical faults, Road condition, Weather condition, Road signs and others appeared as the lowest factors causing RTAs.

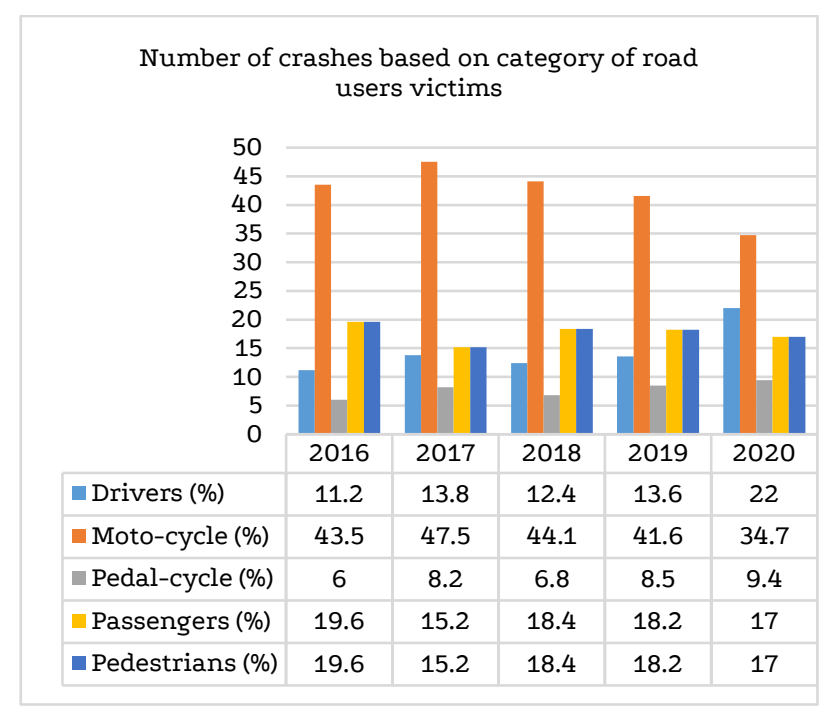

Figure 8. Number of crashes based on the category of road user's victims

Table 4 Figure 8 represent the Number of crashes based on the category of road user victims from 2016 to 2020 . The category of road users were Drivers, moto-cycle, pedal-cycle, passengers, pedestrians with proportions of $11.2 \%, 43.5 \%, 6.0 \%, 19.6 \%$ and $19.6 \%$ in 2016 respectively. In 2017 , the proportions were $13.8 \%, 47.5 \%, 8.2 \%, 15.2 \%$ and $15.2 \%$ respectively. In 2018 , the proportions were $12.4 \%, 44.1 \%$, $6.8 \%, 18.4 \%$ and $18.4 \%$ respectively. In 2019 , the proportions were $13.6 \%, 41.6 \%, 8.5 \%, 18.2 \%$ and $18.2 \%$ respectively. In 2020 , the proportions were $22.0 \%, 34.7 \%, 9.4 \%, 17.0 \%$ and $17.0 \%$ respectively. The results of this study showed that moto-cycle was the most category of road users affected by RTAs in 2016, 2017, 2018, 2019 and 2020 with proportions of $43.5 \%, 47.5 \%, 44.1 \%, 41.6 \%$ and $34.7 \%$ respectively; however pedal-cycle was the minority category of road users affected by RTAs in 2016, 2017, 2018, 2019, 2020 with proportions of $6.0 \%, 8.2 \%, 6.8 \%, 8.5 \%$ and $9.4 \%$ respectively.

\section{Chi-square statistical analysis}

\subsection{Model description}

Chi-square is a statistical test commonly used to compare the observed data with the expect data. İt is also a theoretical or mathematical distribution which has wide applicability in statistical work. In this research work, Chi-square test was performed on total number of fatalities, injuries and PDO, Types of vehicles involved in Road Traffic crashes, Causes of Road Traffic Crashes and Road users victims to assess if they have relationship with RTAs. A chi-square test for independence compares two variables in a contingency table to see if there is relationship between them. In a more general sense, it tastes to see whether distributions of categorical variables differ from each another. 
A very small chi-square value means that your observed data fits your expected data extremely well. In other words, there is a relationship. A very large chi-square value means that the data does not fit very well. In other words, there isn't any relationship.

The following formulas were used to calculate the Expected value and chi-square value:

$\mathbf{E}_{\mathrm{i}, \mathrm{j}}=\frac{\sum_{\mathrm{k}=1}^{\mathrm{c}} \mathbf{o}_{\mathrm{i}, \mathrm{j}} \sum_{\mathrm{k}=1}^{\mathrm{r}} \mathbf{o}_{\mathrm{k}, \mathrm{j}}}{\mathrm{N}}$

Where

$\mathbf{E}_{\mathbf{i}, \mathrm{j}}=$ Expected value

$\sum_{\mathbf{k}=1}^{\mathrm{c}} \mathbf{O}_{\mathrm{i}, \mathrm{j}}=$ Sum of the $\mathrm{i}^{\text {th }}$ column

$\sum_{\mathrm{k}=1}^{\mathrm{r}} \mathbf{O}_{\mathrm{k}, \mathrm{j}}=$ Sum of the $\mathrm{k}^{\text {th }}$ row

$N=$ Total number

After calculating the expected value, the following formula was applied to calculate the value of the Chi-Square test of Independence (Glen, 2020):

$x^{2}=\sum_{\mathrm{i}=1}^{\mathrm{r}} \sum_{\mathrm{j}=1}^{\mathrm{c}} \frac{\left(\mathrm{O}_{\mathrm{i} . \mathrm{j}}-\mathrm{E}_{\mathrm{i}, \mathrm{j}}\right)^{2}}{\mathrm{E}_{\mathrm{i}, \mathrm{j}}}$

Where

$\boldsymbol{x}^{2}=$ Chi-Square test of Independence. $\boldsymbol{O}_{i . j}=$ Observed value of two nominal variables. $\boldsymbol{E}_{i, j}=$ Expected value of two nominal variables

Degree of freedom is calculated by using the following formula:

$\mathrm{DF}=(\mathrm{r}-1)(\mathrm{c}-1)$

Where

$\mathrm{DF}=$ Degree of freedom

$\mathbf{r}=$ number of rows

$\mathbf{c}=$ number of columns

The chi-square test has both a null hypothesis and alternative hypothesis: Null hypothesis; There are no relationship between the categorical variables. If you know the value of one variable, it does not help you to predict the value of another variable. Alternative hypothesis: They are relationship between categorical variables. Knowing the value of one variable does help you predict the value of another variable.

The chi-square test of independence works by comparing the distribution that you observe to the distribution that you extract if there is no relationship between the categorical variables. In the chisquare context, the word "Expected" is equivalent to what you had expect if the null hypothesis is true. If your observed distribution is sufficiently different than the expected distribution (No relationship) you can reject the null hypothesis and infer that the variables are related. For a chi-square test, a p-value that is less than or equal to your significance level indicates that there is sufficient evidence to conclude that the observed distribution is not the same as the expected distribution. You can conclude that the relationship exists between the categorical variables. According to (Statistics solutions, 2021), The Chi-Square test of independence is used to determine if there is a significant relationship between two nominal (categorical) variables. The frequency of each category for one nominal variable is compared across the categories of the second nominal variable. The data can be displayed in a contingency table where each row represents a category for one variable and each column represents a category for the other variable. From the critical value tables corresponding to the calculated degree of freedom as 4 and significance level of 0.05 is found as 9.49 .

4.2. $\chi^{2}$-test to test whether Fatalities, injuries and PDO are related to RTAs

Table 6. Observed, Expected \& Calculated $\chi^{2}$-values for fatalities, injuries and $\mathrm{PDO}$

\begin{tabular}{llllll}
\hline \multicolumn{5}{c}{ Observed Values } \\
\hline Fatalities & 2016 & 2017 & 2018 & 2019 & 2020 \\
Injuries & 10.7 & 10.80 & 11.70 & 15.90 & 12.50 \\
PDO & 53.0 & 64.70 & 67.30 & 77.20 & 48.0 \\
& 36.30 & 24.50 & 21.10 & 6.90 & 39.50 \\
\hline \multicolumn{5}{c}{ Expected Values } \\
\hline Fatalities & 12.32 & 12.32 & 12.33 & 12.32 & 12.32 \\
Injuries & 62.03 & 62.03 & 62.09 & 62.03 & 63.03 \\
PDO & 25.65 & 25.65 & 25.68 & 25.65 & 25.65 \\
\hline Fatalities & 0.21 & 0.19 & 0.03 & 1.04 & 0.003 \\
Injuries & 1.31 & 0.12 & 0.44 & 3.71 & 3.17 \\
PDO & 4.42 & 0.05 & 0.82 & 13.71 & 7.47 \\
Total & 5.94 & 0.36 & 1.29 & 18.46 & 10.65 \\
\hline \multicolumn{5}{c}{$\sum \chi^{2}=36.7$} \\
\hline
\end{tabular}

$\mathbf{H}_{\mathrm{O}}$ : Null hypothesis for calculated chi-square value greater than critical value; it is means that Fatalities, injuries and PDO are related to RTAs.

$\mathbf{H}_{1}$ : Alternative hypothesis for calculated chi-square value less than critical value; indicates that the Fatalities, injuries and PDO are not related to RTAs. The calculated chi-square value was 36.7 which is greater than the critical value of 9.49 , So Fatalities, injuries and PDO are related to RTAs.

\section{3. $\chi^{2}$-test to test whether Vehicle types are related to RTAs}

Table 7. Observed, Expected and chi-square values for vehicle types

\begin{tabular}{|c|c|c|c|c|c|}
\hline \multicolumn{6}{|c|}{ Observed Values } \\
\hline Vehicles & 2016 & 2017 & 2018 & 2019 & 2020 \\
\hline Pickups & 14 & 13.1 & 12.2 & 12.8 & 14.4 \\
\hline Trucks & 10.2 & 11.3 & 12.2 & 11.6 & 14.8 \\
\hline Buses & 11.6 & 9.48 & 8.32 & 8.3 & 7.5 \\
\hline 4 wheel Veh & 15.2 & 14.1 & 12.6 & 12.9 & 14.7 \\
\hline Cars & 23.9 & 22.9 & 19.9 & 18.2 & 17.9 \\
\hline Moto cycles & 22.0 & 24.8 & 30.1 & 30.2 & 25.6 \\
\hline cycles & 3.05 & 4.27 & 4.63 & 6.1 & 7.13 \\
\hline Others & 0.1 & 0.07 & 0 & 0 & 0 \\
\hline \multicolumn{6}{|c|}{ Expected Values } \\
\hline Pickups & 13.3 & 13.3 & 13.3 & 13.3 & 13.31 \\
\hline Trucks & 12.0 & 12.0 & 12.0 & 12.0 & 12.01 \\
\hline Buses & 9.02 & 9.02 & 9.02 & 9.02 & 9.02 \\
\hline 4 wheel Veh & 13.5 & 13.5 & 13.5 & 13.5 & 13.49 \\
\hline Cars & 20.5 & 20.5 & 20.5 & 20.5 & 20.55 \\
\hline Moto cycles & 26.5 & 26.5 & 26.5 & 26.5 & 26.54 \\
\hline cycles & 5.04 & 5.04 & 5.04 & 5.04 & 5.04 \\
\hline Others & 0.03 & 0.03 & 0.03 & 0.03 & 0.03 \\
\hline \multicolumn{6}{|c|}{ Chi Square Values $\left(\chi^{2}\right)$} \\
\hline Pickups & 0.04 & 0.00 & 0.08 & 0.02 & 0.09 \\
\hline Trucks & 0.28 & 0.04 & 0.00 & 0.01 & 0.66 \\
\hline Buses & 0.74 & 0.02 & 0.05 & 0.07 & 0.28 \\
\hline 4 wheel Veh & 0.22 & 0.03 & 0.05 & 0.03 & 0.05 \\
\hline Cars & 0.54 & 0.26 & 0.02 & 0.27 & 0.33 \\
\hline Moto cycles & 0.77 & 0.11 & 0.49 & 0.49 & 0.33 \\
\hline cycles & 0.79 & 0.12 & 0.03 & 0.24 & 0.86 \\
\hline Others & 0.13 & 0.04 & 0.03 & 0.03 & 0.03 \\
\hline Total & 3.51 & 0.62 & 0.75 & 1.16 & 2.63 \\
\hline \multicolumn{6}{|c|}{$\sum \chi^{2}=8.675$} \\
\hline
\end{tabular}


HO: Null hypothesis, for calculated chi square value greater than critical value the vehicle types are related to RTAs.

H1: Alternative hypothesis, for calculated chi square value less than critical value the vehicle types are not related to RTAs.

The calculated chi square value was 8.675 which was less than the critical value of 9.49 , so the vehicle types are not related to RTAs.

\section{4. $\chi^{2}$-test to test whether Causes of Road Traffic Crashes are} related to RTAs

Table 8. Observed, Expected and Calculated $\chi^{2}$ values for causal factors

\begin{tabular}{|c|c|c|c|c|c|}
\hline \multicolumn{6}{|c|}{ Observed Values } \\
\hline Factors & 2016 & 2017 & 2018 & 2019 & 2020 \\
\hline Over speed & 9.3 & 14.7 & 20.3 & 29.2 & 27.3 \\
\hline Over drunk & 2.55 & 3.09 & 3.27 & 3.42 & 2.75 \\
\hline Negligence & 52.1 & 48.3 & 42.3 & 29.4 & 26.2 \\
\hline Bad Maneuver & 33.6 & 32.8 & 33.5 & 37.3 & 42.6 \\
\hline Mecha faults & 2 & 0.89 & 0.47 & 0.49 & 0.92 \\
\hline Road condition & 0.41 & 0.14 & 0.07 & 0.11 & 0.11 \\
\hline Weather cond & 0.04 & 0.02 & 0.07 & 0 & 0.05 \\
\hline Road signs & 0.02 & 0 & 0.02 & 0.03 & 0.05 \\
\hline Others & 0.02 & 0 & 0 & 0.03 & 0 \\
\hline \multicolumn{6}{|c|}{ Expected Values } \\
\hline Over speed & 20.2 & 20.2 & 20.16 & 20.2 & 20.2 \\
\hline Over drunk & 3.02 & 3.02 & 3.02 & 3.02 & 3.02 \\
\hline Negligence & 39.6 & 39.6 & 39.65 & 39.6 & 39.6 \\
\hline Bad Maneuver & 35.9 & 35.9 & 35.97 & 35.9 & 35.9 \\
\hline Mech faults & 0.95 & 0.95 & 0.95 & 0.95 & 0.95 \\
\hline Road condition & 0.17 & 0.17 & 0.17 & 0.17 & 0.17 \\
\hline Weather cond & 0.04 & 0.04 & 0.04 & 0.04 & 0.04 \\
\hline Road signs & 0.02 & 0.02 & 0.02 & 0.02 & 0.02 \\
\hline Others & 0.01 & 0.01 & 0.01 & 0.01 & 0.01 \\
\hline \multicolumn{6}{|c|}{ Chi Square Values $\left(\chi^{2}\right)$} \\
\hline Over speed & 5.85 & 1.47 & 0.001 & 4.06 & 2.53 \\
\hline Over drunk & 0.07 & 0.00 & 0.02 & 0.05 & 0.02 \\
\hline Negligence & 3.88 & 1.89 & 0.17 & 2.65 & 4.55 \\
\hline Bad Maneuver & 0.16 & 0.27 & 0.16 & 0.05 & 1.21 \\
\hline Mech faults & 1.15 & 0.00 & 0.25 & 0.22 & 0.00 \\
\hline Road condition & 0.34 & 0.00 & 0.06 & 0.02 & 0.02 \\
\hline Weather cond & 0.00 & 0.00 & 0.32 & 0.04 & 0.00 \\
\hline Road signs & 0.00 & 0.24 & 0.001 & 0.00 & 0.03 \\
\hline Other & 0.01 & 0.01 & 0.01 & 0.04 & 0.01 \\
\hline Total & 11.5 & 3.9 & 0.99 & 7.13 & 8.37 \\
\hline \multicolumn{6}{|c|}{$\sum \chi^{2}=31.8583$} \\
\hline
\end{tabular}

HO: Null hypothesis, for calculated chi square value greater than critical value the causes of road traffic crashes are related to RTAs.

H1: Alternative hypothesis, for calculated chi square value less than critical value the causes of road traffic crashesare not related to RTAs.

The calculated chi square value was 31.8583 which is greater than the critical value of 9.49 , so the causes of road traffic crashes are related to RTAs.

4.5. $\chi^{2}$ - test to test whether the category of road user's victims are related to RTAs
Table 9. Observed, Expected and Calculated $\chi^{2}$ values for road user victims

\begin{tabular}{llllll}
\hline \multicolumn{5}{c}{ Observed Values } \\
\hline Drivers & 2016 & 2017 & 2018 & 2019 & 2020 \\
Moto & 11.2 & 13.8 & 12.4 & 13.6 & 22 \\
cyclists & 43.5 & 47.5 & 44.1 & 41.6 & 34.7 \\
Passengers & 6 & 8.2 & 6.8 & 8.5 & 9.4 \\
Pedestrians & 19.6 & 15.2 & 18.4 & 18.2 & 17 \\
\hline \multicolumn{5}{c}{ Expected Values } \\
\hline Drivers & 19.6 & 15.2 & 18.4 & 18.2 & 17 \\
Moto & 14.58 & 14.58 & 14.61 & 14.61 & 14.6 \\
cyclists & 42.23 & 42.23 & 42.31 & 42.31 & 42.3 \\
Passengers & 7.77 & 7.77 & 7.79 & 7.79 & 7.79 \\
Pedestrians & 17.66 & 17.66 & 17.69 & 17.69 & 17.7 \\
\multicolumn{7}{c}{17.66} & 17.66 & 17.69 & 17.69 & 17.7 \\
\hline \multicolumn{5}{c}{ Chi Square Values $\left(\chi^{2}\right)$} \\
\hline Drivers & 0.78 & 0.04 & 0.33 & 0.07 & 3.74 \\
Moto & 0.04 & 0.66 & 0.08 & 0.01 & 1.37 \\
cyclists & 0.40 & 0.02 & 0.12 & 0.07 & 0.33 \\
Passengers & 0.21 & 0.34 & 0.03 & 0.01 & 0.03 \\
Pedestrians & 0.21 & 0.34 & 0.03 & 0.01 & 0.03 \\
\hline Total & 1.64 & 1.4 & 0.59 & 0.17 & 5.5 \\
\hline \multicolumn{5}{c}{$\sum \chi^{2}=9.3$} \\
\hline \multicolumn{7}{c}{}
\end{tabular}

HO: Null hypothesis, for calculated chi square value greater than critical value the category of road user's victims are related to RTAs.; H1: Alternative hypothesis, for calculated chi square value less than critical value the category of road users' victims are not related to RTAs. The calculated chi square value was 9.3 which is less than the critical value of 9.49 , so the category of road user's victims are not related to RTAs.

\section{Discussions}

The overall objective of this study was to assess the impact of GERAYO AMAHORO on the reduction of RTAs, case of Rwanda. This point discusses the key findings of this study in the light with different results from other studies done previously. The discussions are based on our research paper objectives. The study done by (Theogene CYIZA and Fred MWASA, 2019) stated that Cars were the most frequent vehicles involved $43.4 \%$ followed by moto-cycles $14.5 \%$ in RTAs which is different from this study shown that moto-cycles were the most frequent vehicles involved in RTAs with $24.81 \%$ (8762) in 2017, 30.13\% (8496) in 2018, 30.15\% (6862) in 2019 and 25.60\% (3536) in 2020 followed by cars with $23.87 \%$ (10454) in 2016. Study done by (Balantine, 2012) revealed that Road design and maintenance is a factor that contributes to road traffic accidents and the causes of road traffic accidents are not just human error or driver negligence while our current study revealed that road condition (road design and maintenance) is not the main factor that contribute to RTAs however negligence is among the main factors contributing to RTAs in Rwanda. With evidence, negligence was the most factor contributing to RTAs in 2016, 2017 and 2018 with proportions of $52.06 \%$ (4894), $48.30 \%$ (4170) and $42.27 \%$ (4071) respectively. With Reference to the increase of RTAs in Rwanda due to Negligence, GERAYO AMAHORO policy was implemented from year 2019 for reducing accidents resulting to Negligence hence the number of accidents caused by negligence was reduced and Bad Maneuver became the most factor contributing to RTAs with 37.29\% (3478) in 2019 and $42.54 \%$ (1853) in 2020 which shows the greatest impact of GERAYO AMAHORO on the reduction of RTAs. (Beckman, 2020) Stated that Environment is also a factor that contribute to RTAs due to the heavy rain which can make road pavement wetting and slide, so its affect the vehicular tires not to resist to slideness on the contrary which is differ from our current research where its results revealed that weather condition (environment) is not the main cause of road traffic crashes contributing to RTAs. The evidence of not having big number of RTAs caused by weather condition in Rwanda is based on that in Rwanda, we do not have heavy rain which can make road pavement wetting and land slide. (A. Patel et al., 2016) Said that the primary vehicle, motorcycles had a 4.47 times increased risk in grievous crashes. 
Similarly, for our study which showed that motor-cycles are primary vehicle types involved in RTAs.

\section{Conclusions}

The study on the impact of GERAYO AMAHORO on road traffic accidents reduction in Rwanda, indicated that GERAYO AMAHORO policy plays the greatest role in reduction of RTAs in Rwanda due to the total number of RTAs happened before the implementation of GERAYO AMAHORO; and it was very high with compared to the total number of RTAs after implementation of GERAYO AMAHORO policy. Secondary data obtained from RNP in the period from 2016 up to 2020 were analyzed, investigated using SPSS and Microsoft excel software.

Examining the total number of Road Traffic crashes by monthly in Rwanda, total number of fatalities, injuries and PDO, types of vehicles involved in Road Traffic accidents, causes of Road Traffic accidents and number of crashes based on category of road users' victims; we can conclude that GERAYO AMAHORO policy plays an important role in reduction of RTAs. The findings were shown on the flow charts analysis for the causes of road traffic crashes, types of vehicles involved, category of road users' victims and the tables for the total number of road traffic crashes, types of vehicles involved in Road Traffic accidents and causes of road traffic accident respectively. Figure-4 Shows that negligence, over speed, bad maneuver and over drunk are the mostly causes responsible for the occurrence of RTAs in Rwanda. Figure- 3 indicates that Vehicle types mostly involved in RTAs were moto-cycles, cars and 4 wheel vehicles. Figure- 5 also indicates that the mostly victims in RTAs were moto-cyclists, passengers and pedestrians. Table- 2 shows the highest mean value of 530.25(6363) with lowest Std. Dev 28.99(6363) of RTAs occurred in 2016; and highest Std. Dev 85.39(4174) with lowest mean 347.83(4174) of RTAs occurred in 2020. This revealed that in 2020, the road traffic accidents reduced due to the measures which were implemented in GERAYO AMAHORO campaign. Table-3 shows the highest mean 1306.75(10454) with the highest Std. Dev 864.40(10454) of RTAs occurred in 2016; and the lowest mean 442(3536) with the lowest standard deviation of $274.15(3536)$ for RTAs occurred in 2020. Table-4 shows the highest mean 543.78(4894) with the highest Std. Dev 919.68(4894) of RTAs occurred in 2016 and the lowest mean 205.89(1853) with the lowest standard deviation of 303.34(1853) of RTAs occurred in 2020. While Table-5 shows the highest mean 543.78(4894) with the highest Std. Dev 919.68(4894) of RTAs occurred in 2016 and the lowest mean 205.89(1853) with the lowest standard deviation of 303.34(1853) for RTAs occurred in 2020.

For chi-square method, $\chi^{2}$-test was used to test whether Fatalities, injuries and PDO are related to RTAs. The calculated chi-square value was 36.7 from Table 1 which is greater than the critical value of 9.49, which means that the Fatalities, injuries and PDO are related to RTAs. $\chi^{2}$-test was also used to test whether Vehicle types are related to RTAs, the calculated chi-square value was 8.675 from Table 2 which was less than the critical value of 9.49, it means that the vehicle types are not related to RTAs. $\chi^{2}$-test was used to test whether Causes of Road Traffic Crashes are related to RTAs, the calculated chi-square value was 31.8583 from Table- 3 which is greater than the critical value of 9.49 , so the causes of road traffic crashes are related to RTAs. $\chi^{2}$-test was utilized to test whether the category of road users' victims are related to RTAs, The calculated chi square value was 9.3 from Table- 4 which is less than the critical value of 9.49 , so the category of road users victims are not related to RTAs. With the increase in utilizing the GERAYO AMAHORO campaign including speed limit control, strict laws on helmets, seat belt usage, discouraging drink driving, use of mobile phones while driving, motor vehicle inspection, even improved road infrastructure. They provided the training to the all road users including drivers, pedestrians, motorcyclists and pedal cyclists; which could help to reduce RTAs as minimum as possible. Although RTAs are being reduced but RTAs accidents are still happening, people are still dying, properties are still destructed; form the point view of analysis and findings, we conclude that the GERAYO AMAHORO policy has to be strictly enforced with laws in order to decrease RTAs as minimum as possible nearby zero.

\section{Acknowledgements}

The authors acknowledge the previous researchers and practionners who contributed in the field of traffic engineering. Many thanks goes to supervisor Prof. Shuai Bin for his significant contribution and guidance. Thereafter the thanks go also to all authors for their significant contributions to complete this work.

\section{Declaration of Conflict of Interests}

The authors declare that there is no conflict of interest. They have no known competing financial interests or personal relationships that could have appeared to influence the work reported in this paper.

\section{References}

[1.] Global status report on road safety (2018).

[2.] Goswami A. and Sonowal R.. (2011). A statistical Analysis of Road Traffic accidents in Dibrugarh City,Assam,India.

[3.] Patel A. et al. (2016). The epidemiology of road traffic injury hotspots in Kigali,Rwanda from police data.

[4.] Goswami, Ajit and Sonowal, Ripunjoy, (2011, January). A statistical analysis of road traffic accidents in Dibrugarh city, Assam, India.

[5.] Balantine, E. (2012, July-December). Road Traffic Accidents in Nigeria:A Public Health Problem, 3.

[6.] Beckman, V. (2020). Reasons why car accidents take place.

[7.] Hunde, Belachew Melese and Aged, Zeleke Dutamo. (2015, December). Statistical analysis of road traffic car accident in Dire Dawa Administrative City. Science journal of applied mathematics and statistics, 3(6), 250-256.

[8.] Chen, G. (2010, jun 08). Road traffic Safety in African countries status,trend,contributing factors,counter measures and challenges. International journal of injury control and safety promotion, 247-255.

[9.] Mohammed, Hussein D., Ahmed, Abbas M. and Ahmed, Heba A. (2015, May). Statistical Analysis of Traffic Accidents Locations Using Geographic Information System in Darbandikhan TownKurdistan Region of Iraq, 6(5)

[10.] Frost, J. (2020). Chi-Square Test of Independence and an Example. Retrieved july 29, 2020, from Statisticsbyjim.com.

[11.] Glen, S. (2020). StatisticsHowTo.com. Retrieved from Chi-square statistic:how to calculate it/distribution.

[12.] Gopalakrishnan, S. (2012, July). A Public Health Perspective of Road Traffi c Accidents, 1(2), 145.

[13.] Habonimana, H. V. (2014). Road network map of Rwanda.

[14.] Hayes, A. (2020, Mars). Chi-Square statistic definition. Retrieved August 1, 2020, from Investopedia.

[15.] Wismans J. et al. (2016, 02 21). Commentary:Status of road safety in Asia. Traffic Injury Prevention, 217-225.

[16.] Balikuddembe J.K. et al. (2017, june). Mainstreaming road safety in the regional intergration of the East African Community to reduce road traffic injuries. African safety promotion, 15, 39-40. 
[17.] Kenton, W. (2019, september 29). Goodness of fit. Retrieved August 1, 2020, from Investopedia.

[18.] Kopits,E.,Cropper,M. (2005). Traffic fatalities and Economic growth.Accident analysis and prevention. 169-178.

[19.] Lucas Alcides Paulo Baptista et al. (2020). Crash Analysis and Modeling of National Wide Road Traffic Networks in AngolaAfrica. International Journal of Traffic and Transportation Engineering, 9, 16-23.

[20.] Ludovic Gicquel et al. (2017, june 01). Description of Various Factors Contributing to Traffic Accidents in Youth and Measures Proposed to Alleviate Recurrence. frontiers in psychiatry.

[21.] (2019). Map of Rwanda. Lonely Planet.

[22.] Karacasu, Murat and Er, Arzu. (2011). An Analysis on distribution of traffic faults in accidents,based on driver's age and gender: Eskisehir case. Procedia Social and Behavioral Sciences, 779-784.

[23.] Poor road design and maintenance can lead to accidents. (2019, september 19). Retrieved july 14, 2020, from https://nashfranciskato.com.

[24.] Road accidents in the U.S. statistic and facts. (2018, june 15).

[25.] Road safety annual report in South Africa 2017. International transport forum, International traffic safety data and analysis group.

[26.] Road safety in Europe. (2020, 06 18). Retrieved from Wikipedia.

[27.] Shyaka, D. I. (2019, March 11). Road Accidents: The leading cause of death and disabilities.

[28.] Statisticssolutions. (2021). Chi-Square Test of Independence.

[29.] Cyiza Theogene, and Mwasa, Fred. (2019, March 18). Are the efforts at reducing Road traffic accident enough?

[30.] Walczyk Thomas. (2012). A Monte Carlo approach for estimating measurement uncertainty using standard spreadsheet software.

[31.] WHO. (2017). Road Traffic Accidents Death in Rwanda.

[32.] WHO. (2018). Global status report on road safety.

\section{How to Cite This Article}

Gatesi, J., Shuai, B., Mutabaruka, J., and Mukamana, R., Study on the Impact of "Gerayo Amahoro Policy" on Road Traffic Accidents Reduction in Rwanda, 4(2021), 1-9.

https://doi.org/10.36937/ben.2022.4197 